\title{
RECAP - A FRAMEWORK TO SUPPORT STRUCTURED REFLECTION IN ENGINEERING PROJECTS
}

\author{
D. Inkermann ${ }^{1, \bigotimes}, M$. Gürtler ${ }^{2}$ and A. Seegrün ${ }^{3}$ \\ ${ }^{1}$ Technische Universität Clausthal, Germany, ${ }^{2}$ University of Technology Sydney, Australia, ${ }^{3}$ Technische \\ Universität Braunschweig, Germany \\ $\triangle$ david.inkermann@tu-clausthal.de
}

\begin{abstract}
Reflection is understood as an integral part of designing and design processes. Despite the high relevance and an ongoing discussion about agile engineering, we found that reflection is rarley established in industrial practice. There is a need for an approach structuring the wide range of levels, stakeholders, objects and timing of reflections. The introduced RECAP framework is an important step towards a guideline (heuristic) for reflection in engineering projects. Based on the four dimensions objectives, stakeholders, objects, and processes it supports structured planning of reflection.
\end{abstract}

Keywords: process improvement, design process, agile product development, reflection, design methods

\section{Introduction}

Our technology, economy, organisations and social systems are deeply affected by dynamic changes, caused by globalisation and digitalisation. Focussing on product development, aside from increasing system complexity, these changes result in high dynamics of customer needs and technology development, and increasing product and market uncertainties (Boehm and Turner, 2004). Since a multitude of changes cannot be foreseen when planning engineering projects, they become triggers for time-consuming iterations and adaptions in running projects. Thus, continuous process improvement becomes a prerequisite for a company's success (Grunwald, 2002; Hollauer and Lindemann, 2017). Here reflection - understood as the ability to recognise what is appropriate and to adapt accordingly becomes a crucial success factor to initiate and handle changes and guide continuous adaption of processes, procedures, and methods used. Although reflection has been denoted as integral part of design activities (Eder and Hubka, 2004) as well as a means to assess activities and take measures for better performance in future design activities (Geis and Birkhofer, 2009), there are rarely concepts to support structured reflection of different stakeholders in engineering projects. Despite the high relevance and an ongoing discussion about agile engineering approaches, we found that on the one hand reflection in industrial engineering projects is only established marginal. On the other hand, there are no approaches in literature taking into account the wide range of levels, stakeholders, objects and timing of reflection. However, Badke-Schaub et al. (2011) stress the importance of defining the right time for such reflection activities, reflecting on the right aspects and involving the right people is crucial for the success of the reflection activity. In addition, despite the benefits of a systematic 
reflection, companies tend to favour action rather than reflection (Daudelin, 1996). This is also aggravated through the lack of approaches to support systematic reflection process in companies. Existing approaches usually show two shortcomings: conceptual models, such as (Schön, 1987; Kolb, 2015) are too abstract to be applied practically; approaches providing specific methods and tools tend to focus on specific use cases and contexts, e.g. (Franken and Franken, 2011; Babb et al., 2014). Moreover, these approaches do not address requirements of engineering design processes. With regard to this contribution, this results in the following research questions:

- What are the drivers for reflection in industrial practice, which objects are addressed and which stakeholders are involved in current reflection practice?

- Which dimensions and level to differentiate reflection activities are described in literature and how can these dimensions be used to plan structured reflections in engineering projects?

To answer these questions, we analyse existing models, procedures, and methods to describe and conduct reflection. Furthermore, we conduct an exploratory interview study to investigate current practice and challenges of reflection in four companies. The theoretical and empirical insights are consolidated into the new framework called RECAP, aiming to support the systematic planning and management of reflection. The proposed framework is an important step towards a methodical guideline (heuristic) to foster reflection in engineering projects. Based on the defined dimensions of reflection it can be tailored to each project and supports companies in planning and managing when to reflect, on what, how and what people to involve in reflection practice.

The structure of this paper is as follows. Section 2 introduces key issues of reflection in product development and provides a structured literature review of existing model and methods to describe and perform reflection. The findings and understandings are used to perform an explorative study, investigating the current state of reflection in industrial practice in Section 3. Section 4 presents the RECAP framework to structure a systematic reflection process. Section 5 concludes the paper, naming the essential contributions and limitations as well as future work of our research.

\section{The role of reflection in product development}

Contemporary product development requires collaboration across disciplines, departments and organisations resulting in an increased coordination and communication effort to react flexibly and quickly to internal and external changes (Meil et al., 2004). This requires effective reflection, i.e. a mechanism to translate experiences into learnings (Boud et al., 1985, Knipfer et al., 2013).

\subsection{Key issues of reflection in product development}

Literature states different issues and challenges of successful reflection. Adapting the barrier categories of Hauschildt and Salomo (2007), based on the promotor model of Witte (1973), these issues can be structured into three categories on an organisational and individual level:

Issues of motivation: A central barrier is the perceived effort of reflection activities. Companies tend to place greater emphasis on action than on reflection (Daudelin, 1996). To avoid the risk of omitting painful or embarrassing lessons learnt, Goffin and Koners (2011) stresses that all key lessons are well documented to allow for successful improvements. This also includes overcoming a lack of action as it is crucial that lessons learnt are applied to future activities and projects (Goffin and Koners, 2011).

Issues of ability: Reflection is a complex and multi-faceted phenomenon (Reymen, 2001, Weixelbaum, 2016, Boud et al., 1985), which can be easily overwhelming. To avoid ad-hoc activities, Reymen (2001) states the benefits of a structured reflection. However, this usually requires existing experience (Schön, 1987), which makes reflection particularly difficult for unexperienced designers, who might need training (Goffin and Koners, 2011). Reflection is also often mentioned as a reactive activity triggered by specific incidents or problems (Prilla et al., 2013) rather than a systematic proactive activity.

Issues of permission: a successful reflection also requires space and time for the reflection as well as the possibility, room and management support for change. Andersen (2015) states that individuals "who constantly question, challenge or "dodge" existing rules, seldom fit into organisational life." Designers need to be empowered to autonomously, flexibly and purposefully manage novel and critical situations in their daily development routine (Weixelbaum, 2016). 


\subsection{Reflection approaches in product development}

This section identifies and analyses existing approaches of reflection concerning aspects, such as timing, levels of detail, content, and process steps. The identified approaches are categorised into conceptual models describing abstract theories and models, generic procedures explaining reflection practice, and specific methods for reflection. The categorisation of the analysed models is presented in Figure 1.

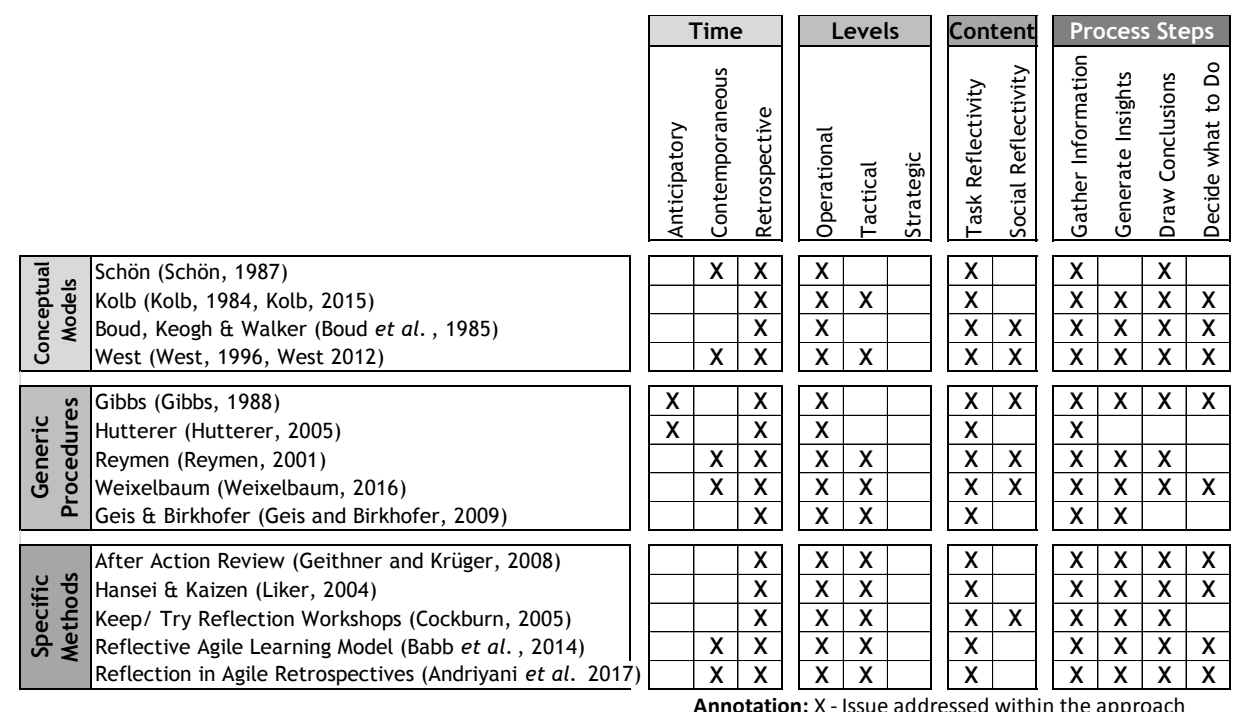

Figure 1. Categorisation of models, procedures and methods based on the factors of time, levels, content, and process of reflection, based on Seegruen (2019)

\subsubsection{Conceptual models of reflection}

Conceptual models provide fundamental understandings, and describe types and processes of reflection. Our literature analysis identified four central and frequently cited models of research on reflection in product development: Schön (1987), Kolb (1984, 2015), Boud et al. (1985), and West (1996). All of them describe reflection as an essential activity to acquire expertise.

According to the team reflexivity approach of West (2012), reflection can be performed before, during and after task processing. While reflection before task processing focusses of the alignment of targets and strategies, reflection during task processing aims at reviewing and adapting existing targets and strategies of the team. Reflection after performing a task comprises a critical evaluation of the achieved results and applied procedures. Similarly, Schön distinguishes between reflection-in-action and reflection-on-action (Schön, 1987). To actively cope with problematic and divergent situations, refection-on-action focusses on the argument with the material of a situation at hand. Reflection-on-action is focussed on the preparation of similar future situations and thus refers to the time horizon of the past. West focusses on team performance and highlights the role of reflection to continuously improve team knowledge, skills and performance West (2012). Kolb (1984) and Boud et al. (1985) place reflection an essential phase within learning cycles. Therefore, in Kolb's experimental learning approach, observations of the reflection process allow for analysing and translating individual experiences, perceptions and assumptions into new-shared insights and concepts. Boud et al. embed reflection in a conscious, experience-based and emotion-led learning process, used to re-evaluate the experience, the behaviour, ideas and feelings (Boud et al., 1985). They highlight that emergence of emotions is often the stimulus for dealing reflectively with a situation.

The conceptual models of reflection provide insights on the basic tasks of reflection and different types with regard to the point of time when reflection is performed and serves as a baseline for generic procedures and specific methods of reflection in product development.

\subsubsection{Generic procedures for reflection}

Generic procedures for reflection provide insights on how to organise reflection and implement reflection practice into product development. Based on the literature review five procedures were identified, see Figure 1. The procedure of Gibbs is based on the models of Kolb and Boud et al. and 
provides practical guidelines and instructions for reflective learning processes (Gibbs, 1988). The proposed reflection cycle comprises the phases description, feelings, evaluation, analysis, conclusions, and action plan. To support the different phases, Gibbs provides a catalogue of questions (Gibbs, 1988). Hutterer's approach of reflective dialogues focusses on identifying needs for methodical support in product development based on self-reflection of the designer (Hutterer, 2005). To improve method application Hutterer focusses on the schemata to be processed successively and provides questions to stimulate self-reflection. Reymen stresses the importance of reflection to improve processes, its results, and competencies of individuals and teams in product development (Reymen, 2001). Three main steps of reflection are defined, namely preparation, image forming, and conclusion drawing. The model places the reflection process between two design sessions and includes looking back (preparation) and forward (image-forming and conclusion drawing). To provide content-related support and practical guidance Reymen elaborated a variety of checklists including questions regarding the product and the process as well as forms to document design sessions (Reymen, 2001). Weixelbaum as well focusses on team reflection and training of reflective competencies in product development teams. The proposed model includes problem diagnosis, aiming at interpreting the current situation with regard to team sensitivity (e.g. mood or fears) and events (e.g. failure, difficulties, disturbances in workflow) and problem solving. The problem-solving step includes formulation of adapted and improved goals for the future and specific measures. Weixelbaum provides a set of guiding questions addressing the time horizons of past, present, and future. Another generic procedure for reflection in product development is described by Geis and Birkhofer (2009). They are proposing a tool to support systematic reflection of designer's actions, helping to assess their situation and thus aiding to improve their procedure in the future. Reflection during the process (reflection-on-action) is seen as a major methodical competence in teams required to adapted ideal to real procedures. Therefore, Geis and Birkhofer provide a checklist for self-reflection including methodical procedures, covering the categories of expert knowledge, selection of methods, adaption of methods, execution of methods, and reflection-on-action.

\subsubsection{Specific methods to support reflection practice}

In addition to the conceptual models and generic procedures, there are specific methods available to support reflection practice in specific development contexts. These methods provide references on how to perform reflection on an operational level, picking up the basic idea of continuous improvement by individuals and organisational learning. The After Action Reviews method therefore, uses four guiding questions to review the target, the performance, the deviations between targets and performance, and the lessons learned at regular intervals (Geithner and Krüger, 2008). Thus, it supports the retrospective analysis of recently completed tasks. The proposed guiding questions are intended to initiate a learning process going beyond the individual level by integrating different stakeholders. In the concept of continuous improvement (Kaizen) reflection is seen as an indispensable precondition to initiate measures (Liker, 2004). Besides structures, processes or products it should be applied to employees and their mistakes, weaknesses and shortcomings (Gorecki and Pautsch, 2014). Therefore, Liker defines 14 management principles including "become a learning organisation by relentless reflection (Hansei) and continuous improvement (Kaizen)" (Liker, 2004). To embed Hansei in company practice reflection meetings (Hansei-kai) are proposed (Brunner, 2014). These can be supported the 5-Why method proposing to ask "why" five times in order to identify the underlying cause of a problem (Liker, 2004).

Agile product development understands reflection as an integral part of a process that should be carried out in regular intervals. Specific methods are presented for instance by the Reflective Agile Learning Model (REALM) (Babb et al., 2014), Keep/ try Reflection Workshops as part of the Crystal methodology (Cockburn, 2005) and the framework of Reflection in Agile Retrospectives (Andriyani et al., 2017). The Reflective Agile Learning Model defines how and at which point of time in agile development processes reflection practice should be integrated (Babb et al., 2014). Therefore, it is distinguished between reflection in course of the action (reflection-in-action) and after action (reflection-on-action). To perform reflection specific methods are proposed including daily stand-ups and retrospectives (reflection-onaction) as well as release planning, collective estimation and iteration planning, and demo and acceptance testing (reflection-in-action). Keep/ Try Reflection Workshops are one measure to implement reflection as an essential property of Crystal projects (Cockburn, 2005). It proposes to capture 
conventions to be maintained, current areas of ongoing problems and actions to be tested out in subsequent cycles. The framework of Reflection in Agile Retrospectives defines three levels of reflection to describe experience, feelings, facts or problems (level 1), examine background information (level 2), and specify a concrete plan to cope with similar situations in the further (level 3). These levels are integrated into a five steps sequence for agile retrospectives including the steps set the stage, gather data, generate insights, decide what to do, and close the retrospective (Andriyani et al., 2017).

Based on the analysis of conceptual models, generic procedures and specific methods, reflection practices are categorised into four factors explained in the following.

\subsubsection{Categorisation of reflection models, procedures and methods}

To categorise reflection models, procedures and methods, we use the following four factors derived from the literature review. Figure 1 presents the categorisation of the analyse approaches:

Time of reflection: Defines the time when conducting reflection. Related to the temporal relation to the situation to be examined, reflection processes can be carried out before (anticipatory), during (contemporaneous) or after (retrospective) the situation to be reviewed.

Level of reflection: Defines the time frame the reflection is addressing. In line with organisational planning levels, it can be distinguished between long-term strategic orientation, medium-term tactical focus and a short-term operational nature.

Content of reflection: describes the matters covered by the reflection. A first selection can be made between task reflexivity (e.g. review of goals, strategies, processes) and social reflexivity (review of interpersonal relations like social cohesion or working atmosphere).

Process of reflection: defines basic steps of a reflexion process. Based on the analysed approaches (Reymen, 2001; Andriyani et al., 2017), the following four steps are used for classification: gather data, generate insights, draw conclusions and decide what to do.

The analysis highlights that all approaches are addressing retrospective reflection, while none of them is addressing all three timing aspects. Regarding the level of reflection it becomes clear, that most approaches address the operational and tactical level, while there is no approach explicitly taking into account the strategic level or is considering process adaption and strategic improvement. Focussing on specific methods and generic procedures this coherent due to their operational character and origin in learning practice and agile product development. All of the reflection approaches are considering task reflexivity with regard to the covered content. Social reflexivity is addressed by Kolb (1984) and West (2012) as well as the generic procedures of Gibbs (1988), Reymen (2001), and Weixelbaum (2016) because of the focus on team aspects. The defined steps for structured reflection are covered by nearly all approaches. Only five approaches do not support definition and decision of what to do, see Figure 1.

\section{Reflection practice - explorative interviews}

Based on the factors of reflection derived from literature, in this section an analysis of reflection practice in engineering projects using semi-structured interviews in four companies is presented. Objective of this explorative study is to understand current practice of reflection, drivers and point in time, involved stakeholders as well as methods and tools used to support reflection in companies.

\subsection{Research methodology and scope}

Reflection practise in industry were analysed by semi-structured interviews with people in four companies, see Figure 2. These interviews were structured in three sections. In the first part (introduction), we record personal data including role of the interviewee in engineering projects, design experience and the individual understanding of reflection. In the second part, we introduce the basic levels of reflection and capture the current practice of reflection in the company using the following guiding questions, derived from the analysis (see section 2.2.4):

1. Is reflection performed in engineering projects in terms of reflection-in-action or reflectionon-action? What are triggers to start reflection within an engineering project? Are there external drivers to perform reflection? 
2. What is the objective of the reflection process and what is derived from the reflection results?

3. Which level is addressed by the reflection (strategic, tactile, and operational)? Who is involved in the reflection process?

4. Are there methods or tools available to support the reflection? Is the reflection procedure guided by predefined process?

Each interview had a duration of 60 minutes; answers were written down in front of the person.
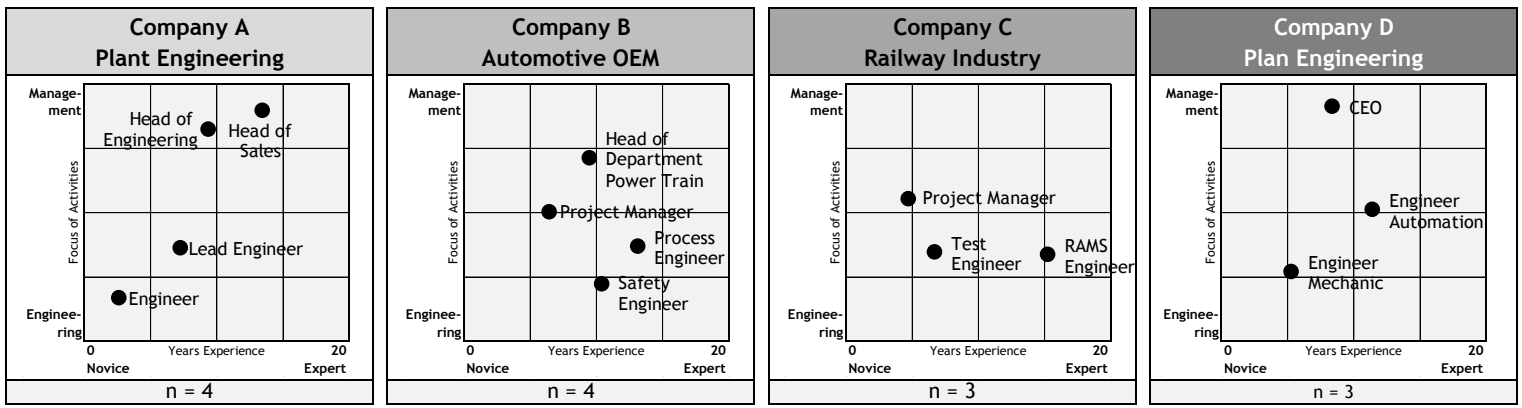

Figure 2. Overview of companies and participants of the explorative interviews

\subsection{Results and insights from interviews in different companies}

Over all 14 interviews in four companies were conducted, see Figure 2. Within the interviews, people with different experiences as well as management and engineering tasks were involved in order to cover the different hierarchical level and different types and objects of reflection.

The information gathered in the interviews were analysed and classified with regard to six categories: type of reflection (in-action/ on-action), triggers for reflection, and objectives of reflection, addressed level of reflection, stakeholders involved, and methods and tools supporting reflection. For each category the information were clustered. For instance, different guiding questions to support reflection were summarized as checklists in the category of methods and tools. In each category, the number of nominations were counted, see Table 1 . The results indicate that most of the reflection practices are focussing on reflection-on-action and thus are conducted after the situation reviewed. Furthermore, in most cases reflection is triggered by external reasons, which are indirectly questioning the current practice of product development regarding quality, time or costs. Further objectives are the information management during projects as well as the improvement of collaboration, including social issues of team composition and responsibilities. With regard to the stakeholders involved in reflection, the focus is on the project team as a unit, while cross project teams (departments) are only partly involved in reflection. To guide reflection, in some cases guiding questions or checklists are used. However, in most of the cases, there are no methods or tools available in companies to support the reflection procedure. One of the key finding is, that in the majority (10 nominations) of the companies reflection is addressing medium-term adaptions and improvements while the operational level is not addressed at all.

Table 1. Issues of reflection reported in the interviews classified into six categories

\begin{tabular}{|c|c|c|c|c|c|c|}
\hline & \multicolumn{6}{|c|}{ Categories } \\
\hline & $\begin{array}{c}\text { Type of } \\
\text { Reflection* }\end{array}$ & $\begin{array}{l}\text { Triggers of } \\
\text { Reflection }\end{array}$ & $\begin{array}{c}\text { Objectives of } \\
\text { Reflection }\end{array}$ & $\begin{array}{c}\text { Level of } \\
\text { Reflection* }\end{array}$ & $\begin{array}{l}\text { Stakeholders } \\
\text { involved* }\end{array}$ & $\begin{array}{l}\text { Methods and } \\
\text { Tools used }\end{array}$ \\
\hline \multirow{5}{*}{$\begin{array}{r}\text { Issues } \\
\text { Reported } \\
\text { and Numbers } \\
\text { of Entries } \\
\text { (see clamps) }\end{array}$} & $\begin{array}{l}\text { Reflection-on- } \\
\text { Action (10) }\end{array}$ & $\begin{array}{l}\text { Delays in Project } \\
\text { Shedule (5) }\end{array}$ & $\begin{array}{l}\text { Improve Quality of } \\
\text { Results (4) }\end{array}$ & Tactic Level (10) & Project Team (11) & $\begin{array}{l}\text { No Methods and } \\
\text { Tools (6) }\end{array}$ \\
\hline & $\begin{array}{l}\text { Reflection-in- } \\
\text { Action (4) }\end{array}$ & $\begin{array}{l}\text { Unsatisfactory } \\
\text { Result Quality (3) }\end{array}$ & $\begin{array}{l}\text { Improve internal } \\
\text { Collaboration (3) }\end{array}$ & Strategic Level (4) & \begin{tabular}{|l} 
Department (Cross \\
Project Team) (4)
\end{tabular} & $\begin{array}{l}\text { Internal Checklists } \\
\text { (5) }\end{array}$ \\
\hline & no Refection (3) & Cost Presure (3) & $\begin{array}{l}\text { Information } \\
\text { Management (3) }\end{array}$ & \multirow{3}{*}{$\begin{array}{l}\text { Cannot allocate } \\
\text { Reflection Practice } \\
\text { to the Levels (3) }\end{array}$} & \multirow{3}{*}{$\begin{array}{l}\text { No Predefinition of } \\
\text { Stakeholder } \\
\text { Involvement (4) }\end{array}$} & $\begin{array}{l}\text { After Action } \\
\text { Review Method (2) }\end{array}$ \\
\hline & & Team Conflits (2) & $\begin{array}{l}\text { Definition of (new) } \\
\text { Responsibilites (2) }\end{array}$ & & & $\begin{array}{l}\text { Projekt Reports } \\
\text { (Diary) (1) }\end{array}$ \\
\hline & & & $\begin{array}{l}\text { Improve Processes } \\
\text { (2) }\end{array}$ & & & \\
\hline
\end{tabular}




\section{The RECAP framework}

Although literature as well as the empirical study highlight the importance of reflection for the effective and efficient management of product development processes, both, their application in practice and existing methodical support are limited. The analysis indicates that reflection approaches do not consider the reflection objects as an issue to be defined explicitly. In fact, the approaches analysed are based on experiences, problematic situations and critical incidents as objects to reflect on. To close this gap, we propose the RECAP framework based on the insights from literature and practice. In order to facilitate a more specific planning and performing of reflection, RECAP aims at supporting in planning specific objectives, stakeholders, objects, process, and timing of reflection within product development projects.

\subsection{Layers of reflection}

To allow for a systematic development of RECAP, different layers of reflection are derived from the literature analysis and mapped to engineering design processes and the general product development context, see Figure 3. Thus, reflection can be carried out on three layers, which directly correlate with the product development context (Bender and Gericke, 2016): a (A) strategic reflection considering long-term context changes, a $(B)$ tactical reflection addressing medium-term changes on a project level, and an $(C)$ operational reflection for short-term changes during a project. Both domains are linked through the domain of engineering processes. On a strategic level, company-specific reference processes structure all product development endeavours of a company as an organisation-specific adaptation of overarching and generic design methodologies (Meißner et al., 2005, VDI, 2019). These processes are specified for each product development project depending on the particular project targets, context and constraints (Meißner et al., 2005). On the operational level, individual process steps and activities are planned, managed and adapted during a project if necessary.

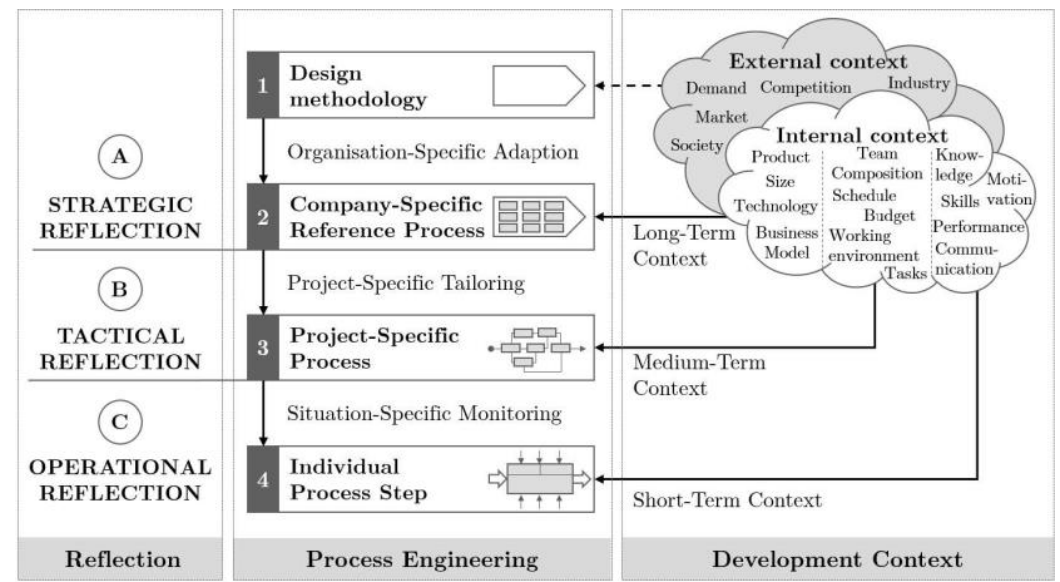

Figure 3. Layers of reflection with regard to the development context

\subsection{Dimensions of reflection within the RECAP framework}

These three layers of reflection form the basis of the RECAP framework (columns in Figure 4). Based on the literature analysis, the following dimensions of reflection were identified: The Objective of reflection characterises the purpose ("Why") of the reflection activity, which directly affects the Stakeholders ("Who") that need to be involved and the Objects to be considered in the reflection process ("What"). As a strategic reflection focuses on adapting overarching reference processes, highlevel stakeholders from the top and middle management need to be involved to reflect on aspects, such as organisational structures and culture. Tactical reflections usually address adaptations of projectspecific processes, which requires stakeholders from process and project management to reflect on projects, teams etc. Due to its focus on individual process steps, operational reflection normally involves project team members, who reflect on particular procedures, individuals and others. The layers also define the Objects of reflection ("What") such as overarching company structures and 
culture on a strategic level, projects and products on a tactical level, and activities and partial results on an operational level. Within this dimension a distinction should be made between objects belonging to the process of the engineering project (see $P$ in hexagon, Figure 4), the goals achieved or to be achieved (see $G$ ), and social aspects like culture, team or communication (see $S$ in hexagon, Figure 4).

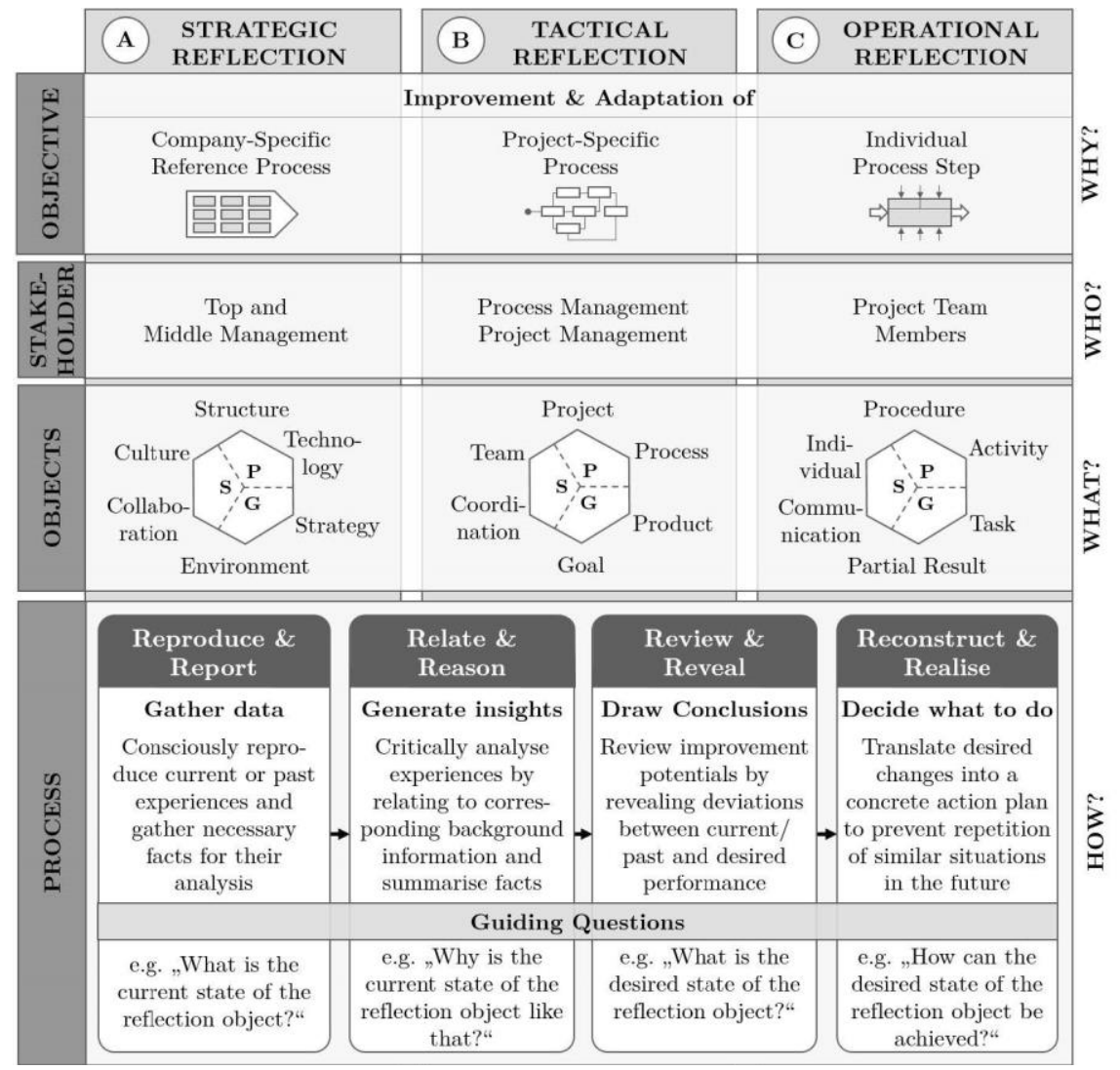

Figure 4. Levels and dimensions within the RECAP framework

The Process of reflection describes "How" specific reflection activities can be conducted. It can be structured in four general steps which apply to all three layers (Schön, 1987; Kolb, 1984; Boud et al., 1985; Gibbs, 1988; West, 1996; Reymen, 2001). The efficiency of each step can be supported by providing guiding questions (Schön, 1987; Gibbs, 1988; Reymen, 2001; Hutterer, 2005; Weixelbaum, 2016). Reproduce and Report gathers necessary data to consciously reproduce current or past experiences of stakeholders and collect data for analysis, for instance around guiding questions like "What is the current state of the reflection objects?". Relate and Reason aims at generating insights through critically analysing data, individual experiences and background information, guided by questions like "Why is the current state of the reflection object like that?". Based on this, the action Review and Reveal draws conclusion through identifying deviations between the desired and actual performance and deriving potential improvements, including guiding questions like "What is the desired state of the reflection object?". Reconstruct and Realise makes a decision about resulting actions through translating desired changes into concrete actions plans, in order to archive improvements and learnings for the future. This includes guiding questions like "How can the desired state of the reflection object be achieved?". Due to considering different layers, the RECAP framework supports a holistic planning and management of reflection in organisations, which does not only focus on, for instance, operational reflection but integrates it with tactical and strategic reflection. From a planning perspective, this allows consistency and traceability of reflection objects, such as single engineering project procedures are feeding into overarching projects and organisational process structures. Moreover, RECAP also supports in identifying the right type of stakeholders for each reflection activity along with guidance around setting up their reflection steps. It also allows reviewing reflection activities themselves of current and previous projects, in order to find the right frequency 
and format of reflection for each company. Detailed guiding questions to define objectives, identify stakeholders and objects within the RECAP framework can be found in (Seegruen, 2019), such as: What were critical incidents related to the focal project? Where and when did the critical incident occur? What did trigger of the critical incident? Have similar incidents happened previously?

\section{Conclusion and further research}

The development process of complex products is more often characterised by unforeseeable events. This uncertainty requires ongoing adaptions in engineering projects with regard to the process, goals and social aspects. An essential precondition for successful adaptations is structured reflection. Despite its relevance, our analysis indicates a lack of strategic and systematic reflection in industry as well as a lack of methodical support to plan and perform reflection in literature. The introduced RECAP framework addresses the current gap of systematic reflection in engineering projects. It is an important step towards a methodical guideline (heuristic), that can be tailored to each project and supports companies in planning when to reflect, on what, how and which people to involve. Moreover, RECAP contributes a framework for a structuring data collection and analysis of research on reflection in engineering design.

The research presented shows several limitations. On the one hand the discipline-spanning literature analysis is challenging because of different terms to describe reflection, which makes a complete analysis difficult. On the other hand the limited number of interviews indicates a serious industry need and some success factors but requires further research to analyse and understand processes, barriers and needs in more detail. Thus, the conceptual RECAP framework presented needs to be applied in practice in order to evaluate, it is applicability as well as effectiveness towards a reflection management heuristic.

Therefore, future research will include a broader interview and case study approach to investigate the current state of reflection in practice along with specific barriers and company needs. In parallel RECAP will be used for planning reflection activities of engineering projects in industry as well as for structuring and analysing observations of the actual project. This will allow to evaluate and adapt the framework and to add details on prescriptive guidance. Moreover, discussing RECAP with experts from other disciplines, such as psychology, will incorporate interdisciplinary research insights and learnings.

\section{References}

Albers, A. and Meboldt, M. (2007), "SPALTEN Matrix - Product Development Process on the Basis of Systems Engineering and Systematic Problem Solving”, in Krause, F.-L. (Ed.), The Future of Product Development, Springer-Verlag, Berlin, Heidelberg, pp. 43-52.

Andriyani, Y., Hoda, R. and Amor, R. (2017), "Reflection in Agile Retrospectives", In: Baumeister, H., Lichter, H. and Riebisch, M. (Eds.), $18^{\text {th }}$ Int. Conf., XP 2017, Cologne, Germany, May 22-26, 2017, Vol. 283, Springer, Cham, pp. 3-19.

Babb, J., Hoda, R. and Norbjerg, J. (2014), "Embedding Reflection and Learning into Agile Software Development", IEEE Software, Vol. 31 No. 4, pp. 51-57.

Badke-Schaub, P., Jaap, D. and Roozenburg, N. (2011), "Towards a Designer-Centred Methodology: Descriptive Considerations and Prescriptive Reflections”, In: Birkhofer, H. (Ed.), The future of design methodology, Springer, London, New York, pp. 181-197.

Bender, B. and Gericke, K. (2016), "Entwicklungsprozesse", In: Lindemann, U. (Ed.), Handbuch Produktentwicklung, Hanser, München, pp. 401-424.

Boehm, B.W. and Turner, R. (2004), Balancing agility and discipline: A guide for the perplexed, Addison-Wesley, Boston.

Boud, D., Keogh, R. and Walker, D. (1985), "Promoting Reflection in Learning" In: Boud, D., Keogh, R. and Walker, D. (Eds.): Turning Experience Into Learning. Oxfordshire, England, pp. 18-40.

Brunner, F.J. (2014), Japanische Erfolgskonzepte: KAIZEN, KVP, Lean Production Management, Total Productive Maintenance, Shopfloor Management, Toyota Production System, GD3 - Lean Development, Praxisreihe Qualitätswissen, $3^{\text {rd }}$ Ed., Hanser, München.

Cockburn, A. (2005), Crystal clear: A human-powered methodology for small teams, The agile software development series, Addison-Wesley, Harlow.

Daudelin, M.W. (1996), "Learning from Experience Through Reflection”, Organizational Dynamics, pp. 36-48. 
Eder, W.E. and Hubka, V. (2004), "Reflection about Reflective Practice", paper presented at The $8^{\text {th }}$ International Design Conference DESIGN 2004, 18-21 May 2004, Dubrovnik, Croatia.

Franken, R. and Franken, S. (2011), Integriertes Wissens- und Innovationsmanagement: Mit Fallstudien und Beispielen aus der Unternehmenspraxis, 1. Ed., Gabler Verlag / Springer Fachmedien Wiesbaden GmbH Wiesbaden, Wiesbaden.

Geis, C. and Birkhofer, H. (2009), "Checklists as Tools for Reflective Practice for Designers", in Proceedings of ICED 09, Palo Alto, CA, USA, 24-27 August 2009, pp. 159-168.

Geithner, S. and Krüger, V. (2008.), "Hochleistungsteams: Lernen durch Reflexion", In: Pawlowsky, P. and Mistele, P. (Eds.), Hochleistungsmanagement: Leistungspotentiale in Organisationen gezielt fördern, Gabler, Wiesbaden, pp. 133-150.

Gibbs, G. (1988), Learning by doing: A guide to teaching and learning methods, Oxford Centre for Staff and Learning Development, Oxford Brookes University, Oxford, United Kingdom.

Goffin, K. and Koners, U. (2011), "Tacit Knowledge, Lessons Learnt, and New Product Development", The Journal of Product Innovation Management, Vol. 28, No. 2, pp. 300-318.

Gorecki, P. and Pautsch, P. (2014), Praxisbuch Lean Management: Der Weg zur operativen Excellence, Hanser eLibrary, 2., überarb. Aufl., Hanser, München.

Grunwald, S. (2002), Methode zur Anwendung der flexiblen integrierten Produktentwicklung und Montageplanung, [PhD-Thesis], Technical University Munich, Munich.

Hauschildt, J. and Salomo, S. (2007), Innovationsmanagement, Fritz Vahlen, Munich.

Hollauer, C. and Lindemann, U. (2017), "Design Process Tailoring: A Review and Perspective on the Literature", In: Chakrabarti, A. and Chakrabarti, D. (Eds.), Proceedings of ICoRD 2017, Springer, Singapore, pp. 609-618.

Hutterer, P. (2005), Reflexive Dialoge und Denkbausteine für die methodische Produktentwicklung, [PhDThesis], Technische Universität München, Munich, Dr. Hut-Verlag.

Knipfer, K. et al. (2013), Reflection as a Catalyst for Organizational Learning, Studies in Continuing Education Vol. 35, No. 1, pp. 30-48.

Kolb, D.A. (1984), Experiential learning: Experience as the source of learning and development, Prentice-Hall, Englewood Cliffs, N.J.

Kolb, D.A. (2015), Experiential learning: Experience as the source of learning and development, $2^{\text {nd }}$ edition, Pearson Education, Upper Saddle River, New Jersey.

Liker, J.K. (2004), The Toyota way: 14 management principles from the world's greatest manufacturer, McGraw-Hill, New York, NY.

Meil, P., Heidling, E. and Rose, H. (2004), "Erfahrungsgeleitetes Lernen bei verteilter Arbeit” In: Böhle, F., Pfeiffer, S., Sevsay-Tegethoff, N. (Eds.), Die Bewältigung des Unplanbaren, Wiesbaden, VS Verlag für Sozialwissenschaften, pp. 180-198.

Meißner, M. et al. (2005), "Eine adaptive Produktentwicklungsmethodik als Beitrag zur Prozessgestaltung in der Produktentwicklung", in Proceedings of the $16^{\text {th }}$ Symposium on Design for X, Neukirchen/ Erlangen, Germany, pp. 67-76.

Prilla, M. et al. "Individual and Collaborative Reflection at Work: Support for Workplace Learning in Healthcare". In Proceedings of 10th International Conference on Computer-Supported Collaborative Learning (CSCL 2013), Madison, WI, USA, June 2013, pp. 121-124.

Reymen, I.M. (2001), Improving Design Processes through Structured Reflection: A Domain-Independent Approach, [PhD-Thesis], Technical University Eindhoven, Eindhoven.

Schön, D.A. (1987), Educating the reflective practitioner: Toward a new design for teaching and learning in the professions, 1. ed., Jossey-Bass, San Francisco, Calif.

Seegruen, A. (2019), Reflective Process Engineering and Method Application in Collaborative Design, [Master Thesis], Technische Universität Braunschweig.

VDI (2019), VDI 2221 Blatt 1:2019-11 Entwicklung technischer Produkte und Systeme - Modell der Produktentwicklung, Beuth-Verlag, Düsseldorf.

Weixelbaum, I. (2016), Mit Teamreflexion zum Teamerfolg: Analyse, Modellierung und gezielte Förderung kollektiver Reflexionsprozesse, [PhD-Thesis], Otto-Friedrich-Universität Bamberg.

West, M.A. (Ed.) (1996), Handbook of work group psychology, Wiley, Chichester.

West, M.A. (2012), Effective teamwork: Practical lessons from organizational research, ${ }^{\text {rd }}$ Ed., BPS Blackwell, Malden, Ma.

Witte, E. (1973), Organisation für Innovationsentscheidungen: das Promotoren-Modell, Göttingen. 